\title{
TINGKAT PENGETAHUAN PERAWAT DENGAN EFEKTIVITAS \\ PENERAPAN MPKP DI RSUD H. A. SULTHAN DAENG RADJA \\ KABUPATEN BULUKUMBA
}

\author{
${ }^{1}$ Muriyati \\ ${ }^{2}$ Safruddin
}

${ }^{1}$ Departemen Keperawatan Medical Bedah Stikes Panrita Husada Bulukumba

${ }^{2}$ Departemen Manajemen Keperawatan Stikes Panrita Husada Bulukumba

\section{Alamat Koresponden:}

Dr. Muriyati,S.Kep,M.Kes

Program Studi S1 Keperawatan

Stikes Panrita Husada Bulukumba

Hp. 085255071407

Email: Muriyati.stikes@gmail.com 


\begin{abstract}
ABSTRAK
Pengetahuan merupakan salah satu faktor yang mempengaruhi pelakasanaan Model Praktik Keperawatan Profesional (MPKP). Fenomena dan kejadian yang terjadi di ruang perawatan Seruni yang menunjukkan bahwa penerapan MPKP masih belum efektif. Dimana terdapat beberapa perawat yang tidak mengetahui apa itu MPKP. Tujuan Penelitian ini adalah untuk mengetahui hubungan tingkat pengetahuan perawat tentang MPKP dengan efektifitas penerapan MPKP di ruangan Seruni RSUD H. Andi Sulthan Daeng Radja Kabupaten Bulukumba 2016. Jenis penelitian ini merupakan penelitian Observasional Analitik dengan rancangan Cross Sectional. Populasi dalam penelitian ini adalah keseluruhan perawat di ruangan Seruni RSUD H. Andi Sulthan Daeng Radja Kabupaten Bulukumba yakni berjumlah 30 orang. Teknik penarikan sampel dalam penelitian ini yaitu dengan cara Total Sampling dengan jumlah sampel 30 responden. Uji statistik yang digunakan adalah Fisher-Extract Test. Hasil penelitian diperoleh bahwa, dalam bentuk tingkat pengetahuan perawat tentang MPKP dengan Efektivitas penerapan MPKP dengan nilai $p=0,045<p(0,05)$. Hasil menunjukkan bahwah responden yang memiliki tingkat pengetahuan yang baik 10 responden $(33,3 \%)$ dan reponden yang memiliki tingkat pengetahuan yang kurang yakni sebesar 20 responden (66,7\%). Penerapan MPKP yang efektif sebesar 12 responden (40\%) dan penerapan MPKP yang tidak efektif yakni sebesar 18 responden (60\%). Dengan Kesimpulan yaitu Ada hubungan tingkat pengetahuan perawat tentang MPKP dengan efektifitas penerapan MPKP di ruangan Seruni RSUD H. Andi Sulthan Daeng Radja Kabupaten Bulukumba 2016. Saran dari penelitan ini diharapakan adanya upaya pengemabangan model praktik keperawatan profesional (MPKP) di setiap rumah sakit khususnya terus mendorong langkah-langkah kongkrit dengan terus meningkatkan frekuensi pelatihan MPKP kepada perawat sehingga penerapan MPKP akan berkesinambungan dengan mutu pelayanan yang baik diperoleh pasien dirumah sakit.
\end{abstract}

\title{
Kata Kunci: Tingakat Pengetahuan, MPKP
}

\begin{abstract}
Knowledge is one of the factors that influence the implementation of the Professional Nursing Practice Model $(M P K P)$. The phenomena and incidents that occurred in the Seruni treatment room showed that the application of MPKP was still not effective. Where there are some nurses who do not know what MPKP is. The purpose of this study was to determine the relationship of the level of knowledge of nurses about MPKP with the effectiveness of implementing MPKP in Seruni Room of H. Andi Sulthan Daeng Radja District Hospital in Bulukumba 2016. This type of research is an Analytical Observational study with a Cross Sectional design. The population in this study were all nurses in the Seruni Room of the H. Andi Sulthan Daeng Radja Hospital in Bulukumba Regency which numbered 30 people. The sampling technique in this study is the Total Sampling method with a sample of 30 respondents. The statistical test used was the Fisher-Extract Test. The results obtained that, in the form of nurses' knowledge level about MPKP with the effectiveness of the application of MPKP with a value of $p=0.045<p(0.05)$. The results show that respondents who have a good level of knowledge are 10 respondents (33.3\%) and respondents who have a lack of knowledge level are equal to 20 respondents (66.7\%). Effective MPKP implementation was 12 respondents (40\%) and ineffective MPKP application was 18 respondents (60\%). With the conclusion that there is a relationship between the level of nurses' knowledge about MPKP with the effectiveness of implementing MPKP in the Seruni Room of the H. Andi Sulthan Daeng Radja District Hospital in Bulukumba 2016. Suggestions from this research are expected to be an effort to develop a model of professional nursing practice (MPKP) in each hospital, especially to continue to encourage concrete steps by continuing to increase the frequency of MPKP training for nurses so that the application of MPKP will be continuous with the good quality of service obtained by patients in the hospital.
\end{abstract}

Keywords: Knowledge Level, MPKP 
PENDAHULUAN

Globalisasi telah memberikan dampak positif bagi setiap profesi kesehatan untuk selalu berupaya meningkatkan kinerja Profesionalnya dalam konstribusi pada berbagai kebutuhan kesehatan masyaraka. Tenaga kesehatan termasuk di dalamnya tenaga keperawatan telah menetapkan arah perkembangan keprofesiannya, arah perkembangan tersebut sejalan dengan ilmu pengetahuan, teknologi kesehatan dan keperawatan yang bertujuan untuk menganstisipasi berbagai perubahan tantangan, dan peluang di era global ini.

Indonesia telah memasuki era baru yaitu reformasi yang ditandai dengan perubahan-perubahan yang cepat disegala bidang menuju pada keadaan yang lebih baik. Pada saat ini kebutuhan masyarakat terhadap pelayanan kesehatan termasuk keperawatan terus meningkat, masyarakat semakin menuntut tersedianya pelayanan kesehatan dan keperawatan dengan kualitas secara profesional dan dapat di pertanggungjawabkan sesuai dengan standar keperawatan yang telah ditentukan.

Menurut Ratna Sitorus (2012) Model Praktik Keperawatan Profesional (MPKP) merupakan stuktur dan proses sistem pemberian asuhan keperawatan pada tingkat ruang rawat sehingga memungkinkan pemberian asuhan keperawatan profesional.

Menurut World Health Organisation (WHO) tidak di jumpai lagi Rumah Sakit di Negara-negara Berkembang yang tidak menggunakan konsep keperawatan manajemen professional. Di amerika selartan (Brasil), Asia Tenggara (Thailland dan Indonesia) dan seluruh sub-sahara benua Afrika tahun 2009 di perkirakan 243 juyta rumah sakit didunia menggunakan model pelayanan ini sebagian besar atau sekitar $85 \%$ terjadi di wilayah afrika kemudian diwilayah Asia Tenggara sebanyak 10\%. (Gaffar, 2012 di kutip dalam Kartika, 2013).

Di Indonesia, layanan prima keperawatan di kembangkan dan diberikan kepada masyarakat dengan menggunakan pendekatan MPKP yang dikembangkan oleh Ratna Sitorus pada tahun 2005 di rumah sakit Ciptokusumo dan di berbagai rumah sakit umum lainnya. Di indonesia di kenal ada dua MPKP yaitu MPKP Umum dan MPKP Jiwa. Pengembangan MPKP merupakan meruapakan upaya berbagai negara untuk meningkatkan mutu asuhan keperawatan dan lingkungan kerja perawat, dan pengembangan MPKP berbeda-beda di setiap negara atau rumah sakit.

Dari hasil penelitian di RSUP DR. Wahidin Sudirohusodo Makassar dan survey JCI (Join Commision International, Januari 2013) mengatakan bahwa di RSUP 
DR. Wahidin Sudirohusodo telah dilaksanakan sistem penerapan MPKP dari tahun 2011 dan berlanjut dengan penerapan SP2KP (Sistem Pemberian Pelayanan Keperawatan Profesional) di beberapa ruangan perawatan (Manajemen RSUP DR. Wahidin Sudirohusodo Makassar, 2013 di kutip dalam Firmanto, 2013).

RSUD H.Andi Sulthan Daeng Radja Kabupaten Bulukumba khususnya di ruang perawatan seruni telah melakukan MPKP sejak tahun 2012. Dan di dapatkan jumlah perawat yang bekerja di ruangan tersebut terdapat 30 orang perawat yang dimana 29 orang perawat telah memiliki STR dan 1 Orang Perawat yang belum memiliki STR. Dan perawat-perawat tersebut telah menempuh jenjang pendidikan Profesi (Ners) sebanyak 10 orang, S1 sebanyak 5 orang dan DIII sebanyak 15 orang.

Menurut Firmanto (2013) dari STIKES Nani Hasanuddin Makassar jurusan keperawatan, telah melakukan penelitian di RSUD H. Andi Sulthan Daeng Radja Bulukumba dengan judul "Perbandingan Penerapan MPKP dan NonMPKP Terhadap Mutu Pelayanan Keperawatan Di Ruang Rawat Inap RSUD H. Andi Sulthan Daeng Radja Kabupaten Bulukumba" dalam hal ini menunjukkan hasil terdapat perbedaan yang signifikan terhadap mutu peleyanan di ruang rawat inap MPKP di banding dengan ruang rawat inat non-MPKP.
Berdasarkan fenomena dan kejadian yang terjadi di ruang perawatan Seruni yang menunjukkan bahwa penerapan MPKP masih belum efektif dimana pelaksanaan Operan, Conference dan Ronde Keperawatan belum berjalan sesuai dengan prosedur. Pada saat pengambilan data awal saya sempat bertanya 5 orang perawat tentang MPKP dan terdapat 3 orang yang tidak mengetahui apa itu MPKP, seperti apa pengaplikasian MKPK di ruangan perawatn tersebut, dan hanya memberikan saran kepada si peneliti untuk bertanya lebih lanjut kepada kepala ruangan dan ketua tim di ruangan tersebut mengenai MPKP tersebut.

Untuk dapat menerapkan MPKP dengan Efektif maka perawat terlebih dahulu harus tahu seperti apa itu MPKP dengan begitu perawat bisa mengaplikasikan MPKP dengan baik dan sesuai prosedur sehingga dapat memberikan asuhan keperawatan profesional kepada pasien. Karena dengan Penerapan MPKP yang efektif maka semua perawat akan tahu bagaimana perkembangan kondisi pasien dan apa saja yang menjadi kebutuhan pasien sehingga ia dirawat di rumah sakit, dengan begitu tidak terdapat lagi keluhan klien tentang mutu pelayanan (kehandala perawat, daya tanggap perawat, jaminan pelayanan keperawatan, empati perawat, dan bukti 
langsung atau wujud asuhan keperawatan) di rumah sakit.

\section{METODE}

MenurutDharma (2011) Desain Penelitian adalah model atau metode yang digunakan peneliti untuk melakukan suatu penelitian yang memberikan arah terhadap jalannya penelitian. Desain Penelitian yang digunakan yaitu Observasional Analitik dengan pendekatan "Cross Sectional Design"untuk melihat adanya Hubungan Tingkat Pengetahuan Perawat Tentang MPKP Dengan Efektivitas Penerapan MPKP. Desain cross sectional adalah desain penelitian analitik yang bertujuan untuk mengetahui hubungan antar variabel dimana variabel independen dan variabel dependen di identifikasi pada satu satuan waktu. Penelitian ini akan dilaksanakan pada bulan Juni 2016 di Ruangan Seruni RSUD H. Andi Sulthan Daeng Radja Kabupaten Bulukumba. Populasi dari penelitian ini yaitu semuaperawat yang bekerja di Ruangan SeruniRSUD H. Andi Sulthan Daeng Radja Kabupaten Bulukumbayakni sebanyak 30 orang. MenurutNoetoatmodjo (2010) Sampel adalah objek yang di teliti dan dianggap mewakili seluruh populasi. Sampel pada penelitian ini adalah semua perawat yang berada di ruang perawatan seruni RSUD H. Andi Sulthan Daeng Radja Kabupaten Bulukumbayakni sebanyak 30 orang. Menurut Sugiyono (2012) Teknik Sampling adalah merupakan teknik pengambilan sampel untuk menentukan sampel yang akan digunakan dalam penelitian. Teknik sampling yang digunakan pada penelitian ini adalah menggunakan Total sampling dimana jumlah keseluruhan populasi di jadikan sampel.

Menurut Dharma (2010) Instrumen Penelitian adalah suatu alat yang di gunakan oleh peneliti untuk mengobservasi, mengukur atau menilai suatu fenomena).Instrumen penelitian yang di gunakan dalam penelitian ini adalah Kuisioner dan Lembar Observasi.Instrumen untuk mengukur Tingkat Pengetahuan Perawat tentang MPKP ini adalah berupa lembar kuesioner dengan menggunakan skala guttment yang berisi beberapa pernyataan. Dan untuk mengukur Efektivitas Penerapan MPKP yaitu menggunakan lembar obsevasi.

Menurut Arikunto (2010) di kutip dalam muhammad (2013) Analisis Univariat disajikan untuk mendeskripsikan variabel bebas dan variabel terikat dengan menggunakan tabel distribusi yang konfirmasinya dalam bentuk presentase. Analisis univariat dalam penelitian ini adalah dalam bentuk distribusi frekuensi dan presentase dengan menggunakan bantuan program komputer.

Menurut Arikunto (2010) Analisis Bivariat merupakan analisa untuk mengetahui interaksi dua variabel, 
baikberupa komparatif, asosiatif, maupun korelatif.Penelitian ini dilakukan untuk mengetahui Hubungan tingkat pengetahuan perawat tentang MPKP dengan efektivitas penerapan MPKP di ruangan Seruni Rsud H.Andi Sulthan Daeng Radja Kabupatenbulukumba Tahun 2016 dengan uji Chi-Square $\left(\mathrm{X}^{2}\right)$ alternatif uji Person Korelasi.

\section{HASIL}

Berdasarkan data dari Tabel. 1. dapat diketahui Umur responden terbanyak berada pada kisaran umur 39-34 tahun sebanyak 13 orang $(43,3 \%)$ dan yang paling sedikit ditemukan pada kisaran umur 23-28 tahun sebanyak 8 orang (26,7\%), distribusi frekuensi responden berdasarkan jenis kelamin dari 30 responden, di temukan sebanyak 2 orang responden yang berjenis kelamin laki-laki dan sebanyak 28 orang reponden yang berjenis kelamin perempuan, distribusi frekuensi responden berdasarkan Status Pernikahan dari 30 responden, di temukan sebanyak 26 orang responden yang telah menikah dan sebanyak 4 orang reponden yang belum menikah, distribusi frekuensi responden berdasarkan Status Kepegawaian dari 30 responden, di temukan sebanyak 12 responden yang PNS dan sebanyak 18 responden yang masih Honorer, distribusi frekuensi responden berdasarkan Jenjang Pendidikan dari 30 responden, di temukan sebanyak 17 responden yang berjenjang pendidikan D3, sebanyak 2 responden yang berjenjang pendidikan $S 1$, dan sebanyak 11 responden yang berjenjang pendidikan Ners.

Pada tabel 2 menunjukkan bahwa dari 30 responden diketahui bahwa sebanyak 10 responden yang memiliki tingkat pengetahuan yang baik dan sebanyak 20 responden yang memiliki tingkat pengetahuan yang kurang tentang MPKP.

Pada tabel 3 menunjukkan bahwa dari 30 responden diketahui bahwa sebanyak 12 responden penerapan MPKP yang efektif dan sebanyak 18 responden penerapan MPKP yang tidak efektif.

Pada tabel 4 menunjukkan bahwa dari 30 responden, terdapat 18 reponden yang memiliki tingkat pengetahuan yang baik tentang model praktek keperawatan profesional (MPKP) dengan penerapan MPKP yang efektif sebanyak 10 responden. Dari hasil uji statistik menggunakan uji Fisher di dapatkan nilai $p$ 0,045 Nilai $p<\alpha$ $(0,05)$ sehingga dapat disimpulkan hipotesis diterima. Hal tersebut menunjukkan bahwa tingkat pengetahuan perawat tentang MPKP memiliki hubungan yang bermakna dengan efektivitas penerapan MPKP di RSUD H. Andi Sulthan Daeng Radja Kabupaten Bulukumba Tahun 2016. 


\section{KESIMPULAN DAN SARAN}

Tingkat pengetahuan perawattentang MPKP yang kurang yaitu sebanyak 20 responden dengan persentase $66,7 \%$. Efektivitaspenerapan MPKP yang menerapkan MPKP tidak efektif yaitu sebanyak 18 responden dengan persentase 60\%. TerdapatHubungan Antara Tingkat Pengetahuan Perawat Tentang MPKP Dengan Efektivitas Penerapan MPKP di Ruangan Seruni RSUD H. Andi Sulthan Daeng Radja Kabupaten Bulukumba dengan nilai $p=0,045<\alpha=0,05$. Saran yang dapa diberikan oleh peniliti untuk semua pihak terkait adalah: Agar penelitian ini dapat dijadikan sebagai tambahan informasi kepada semua pihak khususnya perawat yang bekerja di rumah sakit bulukumba terlebih pada perawat yang bekerja di ruangan perawatan Seruni tentang pentingnya MPKP dalam pelaksanaan pelyanan profesional. Disarankan agar kiranya hasil penelitian ini dapat menjadi referensi, tambahan pengalaman dan pengetahuan mahasiswa yang meneliti masalah yang meningkatkan kualitas pelayanan keperawatan secara profesional.

\section{DAFTAR PUSTAKA}

Bakhtiar, A. (2011). Filsafat Ilmu. Jakarta: PT RajaGrafindo Persada.
Dharma, K. (2011). Metodologi Penelitian

Keperawatan : Panduan

Melaksanakan dan Menerapkan

Hasil Penelitian. Jakarta: CV.

Trans Indo Media.

Firmanto, A. (2013) "Perbandingan Penerapan MPKP dan NonMPKP Terhadap Mutu Pelayanan Keperawatan Di Ruang Rawat Inap RSUD H. Andi Sulthan Daeng Radja Bulukumba", Vol.3 (2) Hal.127-135.

Herlambang, S. \& Murwani, A. (2012). Cara Mudah Memahami Manajemen Kesehatan dan Rumah Sakit. Yogyakarta: Gosyen Publishing.

Jalaluddin. (2014). Filsafat Ilmu Pengetahuan: Filsafat, Ilmu Pengetahuan, dan Peradaban. Jakarta: PT RajaGrafindo Persada. Kartini. (2013). Skripsi “ Hubungan Tingkat Pengetahuan dan Sikap Perawat tentang Model Praktik Keperawatan Profesional (MPKP) dengan Mutu Pelayanan di RSUD SINJAI Kabupaten Sinjai " Muhammad, N. (2014) "Hubungan penerapan model praktik keperawatan profesional dengan kepuasa pasien di ruang interna bawah RSUD Prof Dr. H. Aloei Saboe Kota Gorongtalo". 
Notoatmodjo, S. (2010). Metodologi Cendrawasi RSUD Wangaya

Penelitian Kesehatan. Jakarta: PT. Denpasar

RINEKA CIPTA.

Putra, PE. (2012) "Hubungan Tingkat

Pengetahuan Perawat Dengan

Pelaksanaan Metode Penugasan

Dalam Model Praktik

Keperawatan Profesional (MPKP)

Di RSUD Wates".

Sitorus \& Panjaitan, (2011). Manajemen

Keperawatan: Manajemen

Keperawata di Ruang Rawat.

Jakarta: CV Sagung Seto.

Standar Praktik Keperawatan Indonesia

PPNI (2005).

Sugiharto et al, (2012). Manajemen

Keperawatan Aplikasi MPKP di

Rumah Sakit. Jakart: EGC.

Sugiyono. (2012). Metode Penelitian

Kuantitatif, Kualitatif, dan R\&D.

Bandung: CV. ALFABETA

Syamsuddin et al. (2015) Pedoman Praktis

Metodologi Penelitian Internal

(pendekatan kualitatif, kuantitatif,

pengembangan dan mix-method).

Ponorogo: CV. WADE GROUP.

Undang-Undang No.38 Tentang

Keperawatan (2014)

Wulandari S (2012) "Hubungan

Pelaksanaan MPKP Metode

Penugasan Perawat Primer

Modifikasi Dengan Tingkat

Kepuasan Pasien Di Ruang 
Tabel 1 Distribusi Frekuensi Responden Berdasarkan Umur Perawat Di Ruangan Seruni RSUD H. Andi Sulthan Daeng Radja Kabuapaten Bulukumba

\begin{tabular}{ccc}
\hline Umur (Tahun) & Frekuensi & Persentase (\%) \\
\hline $23-28$ & 8 & 26,7 \\
$29-34$ & 13 & 43,3 \\
$35-41$ & 9 & 30,0 \\
\hline Jumlah & $\mathbf{3 0}$ & $\mathbf{1 0 0}$ \\
\hline Jenis Kelamin & Frekuensi & Persentase (\%) \\
\hline Laki-Laki & 2 & 6,7 \\
Perempuan & 28 & 93,3 \\
\hline Jumlah & $\mathbf{3 0}$ & $\mathbf{1 0 0}$ \\
\hline Status Pernikahan & Frekuensi & Persentase (\%) \\
\hline Menikah & 26 & 86,7 \\
Belum Menikah & 4 & 13,3 \\
\hline Jumlah & $\mathbf{3 0}$ & $\mathbf{1 0 0}$ \\
\hline Status PKepegawaian & Frekuensi & Persentase (\%) \\
\hline PNS & 14 & 46,7 \\
Honorer & 16 & 53,3 \\
\hline Jumlah & $\mathbf{3 0}$ & $\mathbf{1 0 0}$ \\
\hline Jenjang Pendidikan & Frekuensi & Persentase (\%) \\
\hline D3 & 15 & 6,0 \\
S1 & 2 & 43,3 \\
Ners & 13 & $\mathbf{1 0 0}$
\end{tabular}

Tabel 2 Distribusi Frekuensi Responden Berdasarkan Tingkat Pengetahuan Perawat Tentang Model Praktek Keperawatan Profesional (MPKP) Di Ruangan

Seruni RSUD H. Andi Sulthan Daeng Radja Kabuapaten Bulukumba

\begin{tabular}{ccc}
\hline Tingkat Pengetahuan & Frekuensi & Persentase (\%) \\
\hline Baik & 10 & 33,3 \\
Kurang & 20 & 66,7 \\
\hline Jumlah & $\mathbf{3 0}$ & $\mathbf{1 0 0}$ \\
\hline
\end{tabular}

Tabel 3 Distribusi Frekuensi Responden Berdasarkan Efektivitas Penerapan Model PraktekKeperawatan Profesional (MPKP) Di Ruangan Seruni RSUD H. Andi Sulthan DaengRadja Kabuapaten Bulukumba Tahun 2016

\begin{tabular}{ccc}
\hline $\begin{array}{c}\text { Efektivitas Penerapan } \\
\text { MPKP }\end{array}$ & Frekuensi & Persentase (\%) \\
\hline Efektif & 12 & 40 \\
Tidak Efektif & 28 & 60 \\
\hline Jumlah & $\mathbf{3 0}$ & $\mathbf{1 0 0}$ \\
\hline
\end{tabular}


Tabel 4 Hubungan Tingkat Pengetahuan Perawat Tentang MPKP Dengan Efektivitas MPKP Di Ruangan Seruni RSUD H. Andi Sulthan Daeng Radja Kabuapaten Bulukumba

\begin{tabular}{|c|c|c|c|c|c|c|c|}
\hline \multirow{3}{*}{$\begin{array}{c}\text { Tingkat } \\
\text { Pengetahuan }\end{array}$} & \multicolumn{3}{|c|}{$\begin{array}{c}\text { Efektivitas Penerapan } \\
\text { MPKP } \\
\end{array}$} & \multicolumn{3}{|c|}{ Total } & \multirow[t]{2}{*}{$P$} \\
\hline & \multirow{2}{*}{$\begin{array}{c}\text { Efektif } \\
(\mathbf{n})\end{array}$} & \multicolumn{2}{|c|}{$\begin{array}{l}\text { Tidak } \\
\text { Efektif }\end{array}$} & & & & \\
\hline & & $(\%)$ & (n) & $(\%)$ & (n) & $(\%)$ & \\
\hline Baik & 7 & 23,3 & 3 & 10,0 & 10 & 33,3 & \\
\hline Kurang & 5 & 16,7 & 15 & 50,0 & 20 & 66,7 & 0,045 \\
\hline Jumlah & 12 & 40 & 18 & 60 & 30 & 100 & \\
\hline
\end{tabular}

